\title{
Fabrication of Tungsten Trioxide-loaded Titania Nanotubes as a Potential Photoanode for Photoelectrochemical Cell
}

\author{
Nur Farah Atikah binti Harun, ${ }^{1}$ Yusairie bin Mohd, ${ }^{1}$ Lim Ying Pei, ${ }^{2}$ Lim Ying Chin ${ }^{1 *}$ \\ ${ }^{1}$ School of Chemistry and Environment, Faculty of Applied Sciences, Universiti Teknologi MARA, \\ Shah Alam, 40450 Selangor, Malaysia. \\ ${ }^{2}$ Faculty of Chemical Engineering, Universiti Teknologi MARA, Shah Alam, 40450 Selangor, \\ Malaysia. \\ *E-mail: $\underline{\text { limyi613@ salam.uitm.edu.my }}$
}

doi: $10.20964 / 2018.05 .19$

Received: 23 November 2017 / Accepted: 28 February 2018 / Published: 10 April 2018

This study aimed to investigate the effect of deposition potential on the growth of tungsten trioxide electrodeposited onto titania nanotubes (WTNT) in a fixed solution $\mathrm{pH}$ of 1.5 as well as its effect on the photoelectrochemical (PEC) properties of titania nanotubes (TNT). Well-ordered crystalline TNT and WTNT were obtained via anodization of titanium foil and electrodeposition of $\mathrm{WO}_{3}$ species respectively as proven via FESEM, EDX, and XRD analyses. All WTNTs showed enhanced PEC performance compared to the blank TNT. WTNT/ $-0.65 \mathrm{~V}$ prepared under deposition potential at -0.65 $\mathrm{V}$ exhibited the highest PEC performance $(\eta=9.63 \%)$ compared to other WTNTs and almost 6 times higher compared to blank TNT $(\eta=1.65 \%)$. Such enhancement was due to optimal amount and morphology of tungsten trioxide deposited which enabled efficient synergetic effect between tungsten trioxide and TNT.

Keywords: charge transport, electrodeposition, nanocomposites, titania nanotubes, photoelectrochemistry

\section{FULL TEXT}

(C) 2018 The Authors. Published by ESG (www.electrochemsci.org). This article is an open access article distributed under the terms and conditions of the Creative Commons Attribution license (http://creativecommons.org/licenses/by/4.0/). 